\title{
Evaluation of impact of one dose Varicella vaccine on the incidence of chickenpox in Argentina
}

\author{
Guillermo G. Barrenechea ${ }^{\mathrm{a}, \mathrm{b}}$, Leonardo S. Bastos ${ }^{\mathrm{c}, \mathrm{d}}$ \\ ${ }^{a}$ Departamento Bioquímico-Laboratorio de Salud Pública, Mendoza $1284^{\circ}$ Piso, San Miguel de \\ Tucumán, Tucumán CP: 4107, Argentina

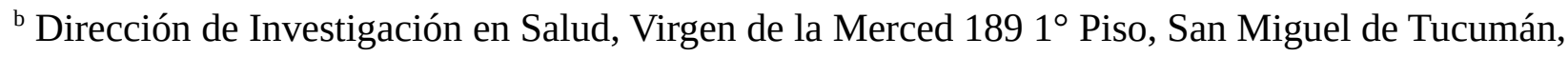 \\ Tucumán CP: 4107, Argentina
}

c Scientific Computing Program, Oswaldo Cruz Foundation, Av. Brasil, 4365, Manguinhos, Rio de Janeiro CEP: 21040-900, Brazil

${ }^{\mathrm{d}}$ Department of Infectious Disease Epidemiology, London School of Hygiene and Tropical Medicine, Keppel Street, London WC1E 7HT, UK

\section{Summary}

Introduction. Varicella, also known as chickenpox is one of the most common immunizable diseases. In 1998, the World Health Organization (WHO) recommended to incorporate this vaccine in the national immunization programs, which Argentina did in 2015. Objectives. To describe the behavior of the varicella time series for the 2005-2017 period, and to evaluate the impact of the vaccine in Argentina. Methodology. An ecological observational study was performed, using the varicella cases reported in the National Health Monitoring System, and the data of the National census as secondary data sources. A model based time series analysis of the notified varicella cases in Argentina was performed, using a Negative Binomial Mixed Model. For the verification of the vaccine impact, the 2005-2014 period was selected, and a prognosis for the following years was performed. Impact was evaluated by comparing the rates and confidence intervals between the predicted and observed values. Results. Argentina reported 1,775,587 varicella cases for the 20052017 period. The series exhibited seasonality, and, a decreasing trend in the number of cases was observed in 2016 and 2017. A reduction of the incidence rate after the implementation of the vaccine was observed. The transmission risk decreased in the country after vaccine implementation. Conclusions. This study is the first concrete evidence of the varicella incidence decline after the implementation of a single dose application program in Argentina.

Keywords: Varicella , Time Series Studies, Chickenpox Vaccine, Health Impact Assessment, Public Policies.

\section{INTRODUCTION}

Varicella, also known as chickenpox is a highly infectious disease caused by the varicella-zoster virus (VZV), a human herpesvirus. It is an often benign, common disease in childhood, associated to fever and generalized itchy vesicular rash, with high rates of secondary attack (1). The Attack Rate (AT) measures the probability of occurrence of an event. Secondary Rate Attack (SRA) is the ratio of new cases of disease among contacts exposed to a primary case. As it is characteristic of alpha herpesvirus, VZV establishes latency after primary infection (2) (3) (4). Both varicella and herpes zoster (HZ) are associated to a high medical, economical and social burden (5) (6).. 
Varicella has a global distribution. Certain reports describe an incidence rate of 270 per 100,000 inhabitants, with a hospitalization rate of 3.5 per 100,000 inhabitants in Latin America (7). However, varicella is not under mandatory report in all countries (8). Argentina reports an approximate rate of 250-450 cases for every 100,000 inhabitants, with children under 10 years old as the most affected age-group, and children between 12 to 23 months, and 24 to 48 months as those with the highest incidence rates. In such report, 272 deaths were recorded between 1997 and 2012, of which $60 \%$ corresponded to children under 10 years (9).

In many countries, varicella is characterized by a seasonal pattern, and by being one of the most common immunizable diseases. It has a strong seasonality with a maximum incidence in late spring in temperate climates and in the coldest and driest months in tropical climates. Likewise differences in the epidemiology of the disease between temperate and tropical climates are different. Argentina reports the association between the behavior of Varicella and climatic variables (10).

The implementation of public policies, such as the systematic application of the vaccine at the population level, aims at reducing varicella morbidity and mortality, and at reaching a quick level of herd immunity. Thus, the universal and free application of the vaccine in children has a herd immunity effect on the non-vaccinated population (11).

The first vaccine was developed in 1974 by Takahashi, from live attenuated viruses to prevent varicella (OKA strain) (12). In 1984, GlaxoSmithKline (OKA/GSK strain) registered its vaccine in many European countries. In 1995, Merck Sharp and Dohme (OKA/Merck strain) registered it in the United States for use in children and healthy adults (13). It is based on a preparation made from the OKA strain of the virus, obtained from the gallbladder of children with varicella attenuated through a serial propagation in cell cultures. It is highly immunogenic in susceptible children, with a sero-conversion higher than 96\% between the ages of 1 and 12 (14).

In 1998, the World Health Organization (WHO) recommended that each country analyze to incorporate the varicella vaccine in the national vaccination programs, and the Argentinean Ministry of Health incorporated such vaccine through the Ministerial Resolution 1,029/2014 published in the Official Journal of July, 15 2014. Such resolution states the incorporation of the varicella vaccine in children aged fifteen (15) months to the National Control Program of Immunizable Diseases; and that the vaccine is universal, free and mandatory starting from 2015 (15) (16). Unlike other countries, which comprise two vaccine doses, in Argentina a single monovalent dose is given at 15 months old, such as in Costa Rica, Ecuador, Paraguay, New Zealand and Niue (17).

In Argentina, the live attenuated varicella-zoster virus vaccine OKA single dose strain OKA/Merck obtained from human diploid cell cultures WI-38 and MRC5 has been used since 2015. It is administered free of charge and universally to all children aged 15 months. In 2016, coverage 
averaged $74 \%$ nationally (whole country), ranging from $46.6 \%$ in Corrientes province to $100 \%$ in Tucumán province. In 2017, the minimum coverage was increased to 53.8\% in Entre Ríos province and several provinces exceeded 90\% (18).

Once the vaccine is implemented, it is necessary to evaluate it and verify its impact. Thus, in the present study, we aimed at evaluating the impact of the vaccine on varicella incidence in Argentina. The specific objectives were: 1- to describe the time series of varicella in Argentina for the 20052017 period; and 2- to evaluate the impact of the vaccine implementation in Argentina.

Traditionally, the evaluation of these types of public policies are made through ecological time series studies, in which the response variable depends on its behavior in the prior periods. This approach allows researchers to identify, explain and predict the effects of the carried-out programs and policies in time (19). However, by definition, a series of an infectious diseases counts exhibits temporal dependence .Our study uses a model-based approach based on a Negative Binomial Mixed Effects model where the temporal dependence is taken into account.

\section{METHODOLOGY}

It was an ecological observational study performed in Argentina from 2005 to 2017. The data came from secondary data sources: 1 - Varicella cases, defined as the number of events reported to the national epidemiological monitoring system within the 2005-2017 period; 2 - Population data from the 2001 and 2010 Argentinian censuses, and population projections from Instituto Nacional de Estadísticas y Censos (INDEC) (20) (21).

The varicella cases came from the Argentinean epidemiological surveillance system. In each province there are notification nodes that are homogeneously distributed in each of province. Physicians from the different Hospitals and Primary Health Care Centres attend to patients and record the pathologies for which patients consult in the services. Each of these institutions functions as a notification node. Varicella cases are mandatory to be reported. The majority of the cases are clinically diagnosed only and are reported on a weekly basis, aggregated by age and sex, by the notification nodes to a national level surveillance system. The consolidated data used in this study come from national surveillance system.

For the data analyses, consisted in two steps: (i) a descriptive time series analysis of varicella cases in Argentina; (ii) a model-based approach to verify the impact of the vaccine in Argentine. All analyses were performed in the R software (22).

The model-approach consisted in fit a generalized linear mixed model with a negative binomial distribution to the number varicella cases by week. The logarithm of the expected number of cases 
is given by the logarithm year population as offset, added by week and year random effects, the week random effects can be used to represent the varicella seasonality in a given year and the year random effects control the heterogeneity among the years and can be used to estimate a possible trend throughout the years. The year random effects are assumed to follow a zero mean independent Gaussian distributions with a common variance, and the week random effects is assumed to be a cyclic second order random walk process in order to induce the temporal dependence, these random effects control heterogeneity among years caused by unmeasured variables such as climate variation. The cyclic component is important to inform the model that the 52th week of a year precede the first week of the following year. The model does not have an intercept, this allows us to interpret the exponential of the week random effects as the expected number of cases by week in a year without vaccination. The model specification is then completed by uninformative priors to the precision parameters of the random effects and for the negative binomial scale parameter. The inference is based on the posterior distribution calculated using the INLA method (23) (24).

For the verification of the vaccine impact, we built our model using data from the non-vaccination period i.e. from 2005 to 2014 . Assuming there is no annual trend on the varicella incidence, the week random effects would represent the expected number of cases in a year without vaccination. Year 2014 was used as a cut-off point, since the vaccine was implemented in 2015. The vaccine impact was evaluated by comparing by year the weekly observed varicella incidence rates with the expected number of cases assuming no-vaccination and the uncertainty in represented their respective 95\% credible intervals obtained from the model.

Among the ethical considerations, since this is an observational study it does not imply interventions or direct contact with patients. Data confidentiality was respected at all times, according to the National Law $\mathrm{N}^{\circ} 25,326$ of personal information protection (25). In that sense, the present study is characterized by the use of non-linked data and health records officially acknowledged by health authorities. This study is approved by the Ethics Committee in Health Research, which depends on the Ministry of Health of Tucumán, Argentina.

\section{RESULTS}

Argentina, reported 1,775,587 varicella cases between 2005-2017. Figure 1 presents weekly reports of varicella in the aforementioned period. The series of notified cases presents a seasonality component with higher values being observed mostly on the second semester of each year, with a first peak on the number of cases occurring approximately in July, and a second and higher peak around October. Before the vaccination starts, in 2015, there is no clear trend and three years, namely 2009, 2012, and 2014, were years with lower number of cases with comparison to the other 
years. On the other hand, after the vaccination starts, there is a trend on reducing the number of cases. The average number of varicella cases per year before 2015 was 146,130, and the following years the number of reported cases were 138,053 in 2015, 96,081 in 2016, and 80,152 in 2017.

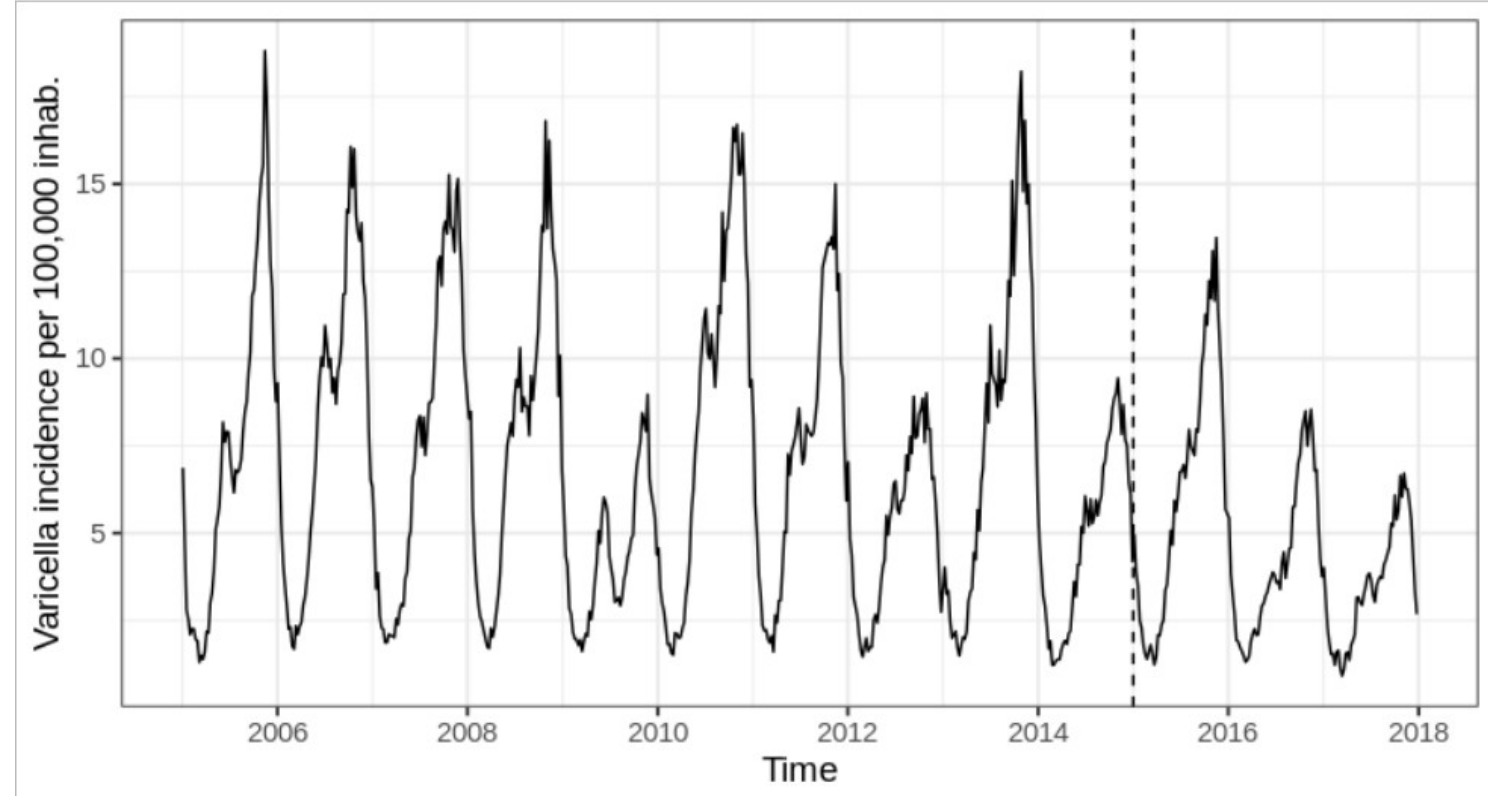

Figure 1: Weekly varicella reported cases in Argentina from 2005 to 2017. The vertical dotted line indicates the beginning of the period when a single dose varicella vaccine become universally available to 15 month old children.

The proposed negative binomial mixed model was fitted for the number of varicella reported cases before 2015. In Figure 2 (a) we estimate that lowest weekly (log)-incidence occurs in week 10 (March), then it increases reaching a first peak in week 25 (July) and reaches the highest incidence after week 40 (October). The year random effects are presented in Figure 2 (b) showing that the years 2009, 2012 and 2014 presented a lower incidence compared to other years which do not present a clear trend.

(a)

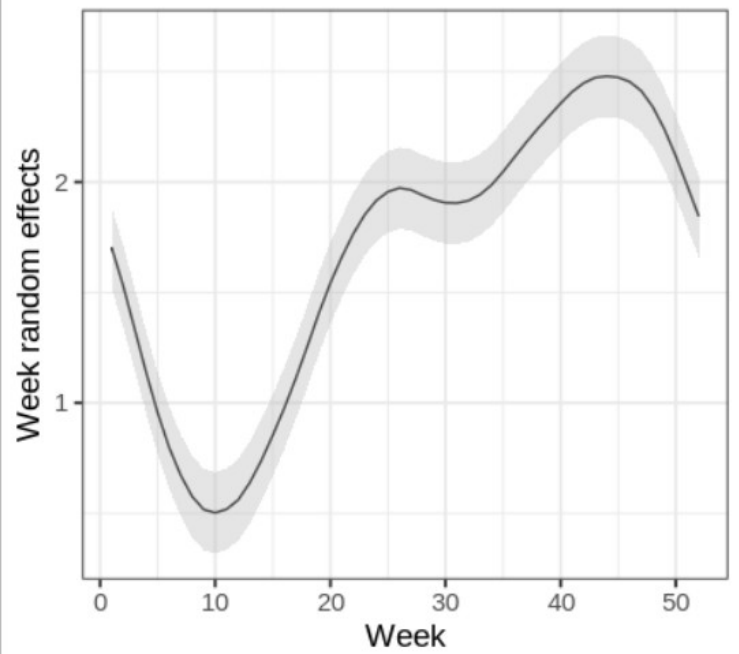

(b)

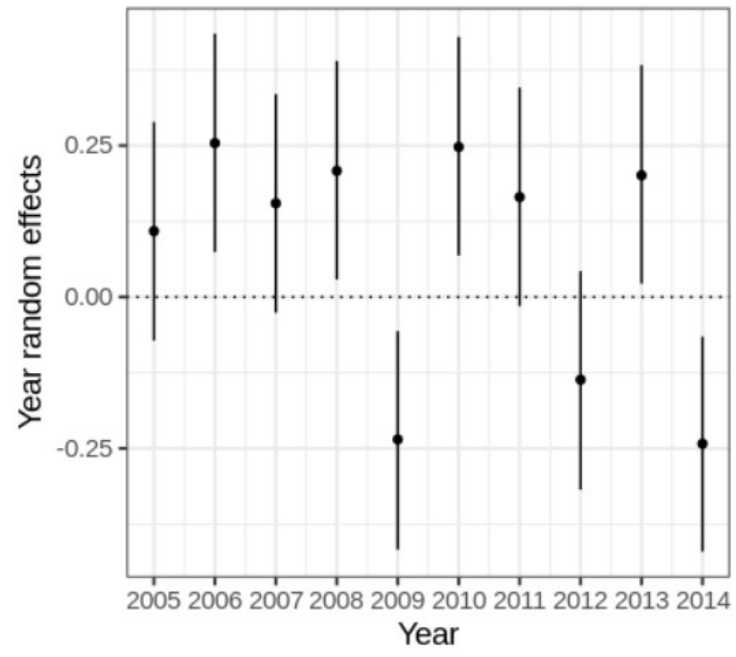

Figure 2: Estimated random effects. (a) Week random effects; (b) Year random effects. 
Since there is no clear yearly trend in the varicella incidence rates before 2015, we use our model built with 2005 to 2014 data to forecast the next years three years ahead, i.e. 2015 to 2017, assuming there is no vaccination. According to our model, we would expect a total of 360.4 (95\% CI 337.4; 383.4) varicella cases per 100,000 inhabitants, which is higher than observed in years after the vaccination started. Figure 3 presents the observed incidence rates and the model-based weekly forecasts assuming no vaccination. There is no evidence on reduction on the incidence rates due to the vaccine introduction in 2015. However, in 2016 the number of cases was below the expected without vaccination and the decline was more pronounced in the year of 2017 (Table 1). This result suggests a significant decline of the varicella incidence rates in Argentina. If we compare the observed annual incidence in 2017 with the expected incidence without vaccination we see a reduction of approximately $50 \%$ on the incidence rates corresponding to a total of 78,580 (95\% CI $68,465 ; 88,695)$ cases avoided. Despite the reduction on incidence rates, the periodicity of the varicella case remains similar after vaccination with the incidence rate peak occurring approximately in October each year.

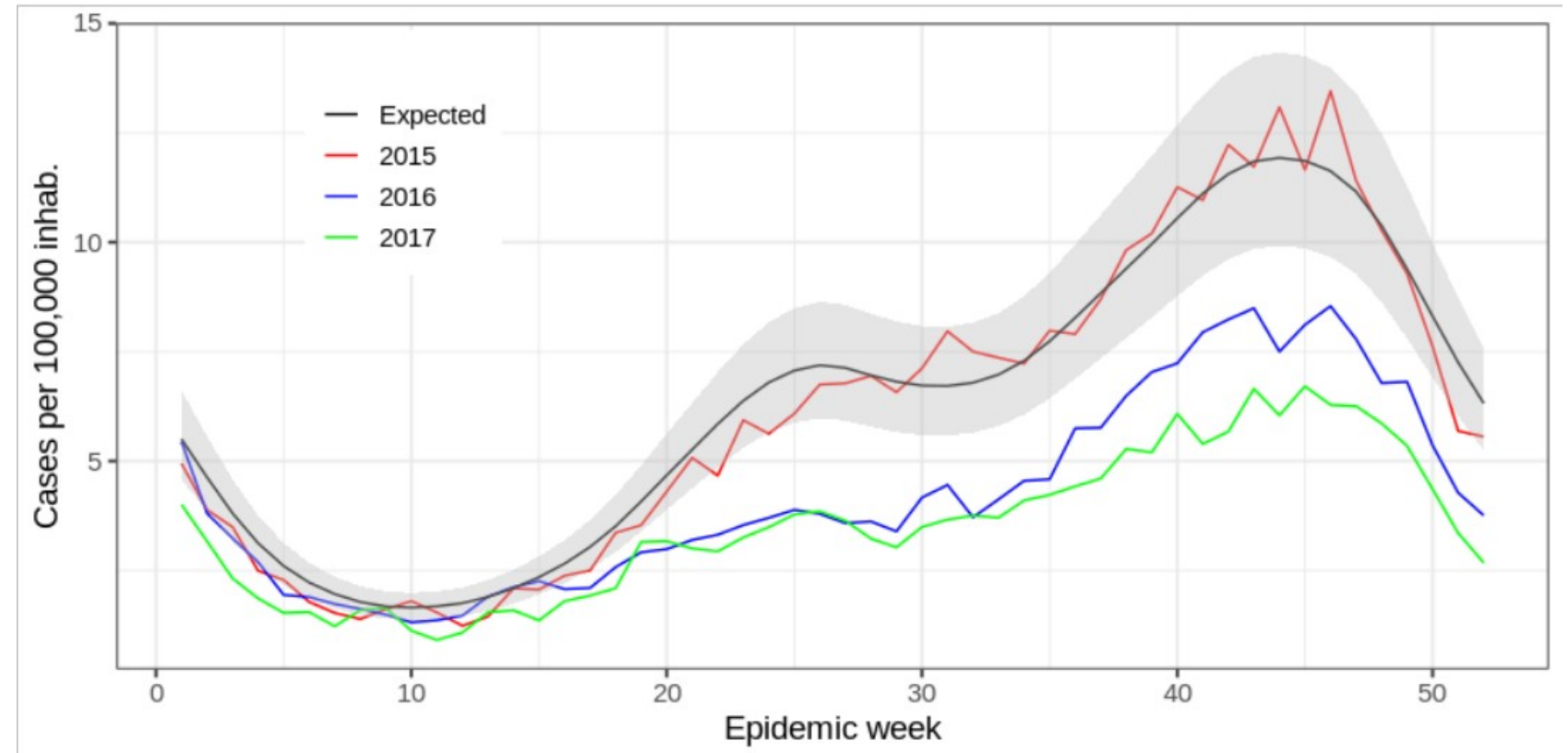

Figure 3: Varicella cases after the introduction of the one dose varicella vaccine. The expected number of cases (black line) are the model-based estimates assuming no vaccination, the uncertainty around these estimates are presented in grey by the $95 \% \mathrm{CI}$. The coloured lines are the observed number of cases in 2015 (red), 2016 (blue) and 2017 (green). 


\begin{tabular}{cccc}
\hline Years & Total varicella cases & $\begin{array}{c}\text { Annual observed } \\
\text { incidence }\end{array}$ & $\begin{array}{c}\text { Annual estimated } \\
\text { incidence (95\% CI) }\end{array}$ \\
\hline $2005-2009$ & 723,239 & 368.1 & $367.3(365.3 ; 369.3)$ \\
\hline $2010-2014$ & 738,062 & 354.5 & $350.7(348.8 ; 352.6)$ \\
\hline 2015 & 138,053 & 320.1 & $270.0(243.7 ; 296.3)$ \\
\hline 2016 & 96,081 & 220.4 & $282.9(242.3 ; 323.4)$ \\
\hline 2017 & 80,152 & 182.0 & $296.5(242.0 ; 351.0)$ \\
\hline
\end{tabular}

Table 1. Total reported varicella cases, the observed annual incidence rate and model-based annual incidence rates with 95\% CI. For the periods 2005-2009 and 2010-2014, we present the average of the annual incidence rates during each period.

\section{DISCUSSION}

This is the first study in Argentina, and one of the few reports in Latin America, showing the national impact of the implementation of a single universal dose of the varicella vaccine. A description of the varicella time series in the pre-vaccine era was obtained, and the impact of the vaccine implementation became clear. A significant reduction of varicella incidence rates, were registered at the national scale. These evidences show the importance of this type of studies to endorse the application of public policies with scientific sound evidence.

In many countries, the incorporation of this vaccine is not mandatory or universal. This is the case in Japan, where before the universal immunization vaccination coverage was $40 \%$, and varicella infection was not controlled (26). More recent epidemiological descriptions report a sharp decrease compared to previous years, which coincides with the increase in coverage through a two-dose vaccine regime resulting from governmental funding. After the implementation, evidence emerged recommending two vaccine doses, which also reported that coverage rates were low (27). It is also observed that countries which suspend the vaccine recommendation or gratuity exhibit an increase on the disease incidence, with higher viral circulation (28).

Until 2015, only nine countries had incorporated the vaccine to their schemes, and only Uruguay (1999) and Costa Rica (2007), the first two countries to implement it, had registered its impact in Latin America (29) (30). Argentina, like other countries, implemented the application of a single dose in its scheme since 2015. The reports of such countries demonstrate an impact of the implementation of the vaccine on incidence reduction, disease burden and hospitalizations due to complications, as occurred with hospitalization rates due to Herpes zoster in the general population (30) (31) (32) (33). On the other hand, evidence shows that although the vaccine is effective in decreasing varicella incidence, it might still not be enough to prevent outbreaks (34). Further, evidence shows that a single varicella dose brings a high protection against moderate to severe 
varicella , but two doses are required for an optimal protection, especially to reduce the risk of epidemic outbreaks (35) (36). A two-dose program might guarantee a high effectivity at the population level; however, comparative models of 1 dose versus 2 doses evidence that this depends on the efficiency of the first dose, and on the impact that it might have on zoster (37). Likewise, the impact on incidence decrease might affect specific cohorts, through the accumulation of the sensitive individuals among the non-vaccinated population, who might get the disease later in their life, as well as the behavior of the herpes zoster (HS) (38) (39). In that sense, one of the possible impacts of mass varicella vaccination is that an increase in herpes-zoster could be expected during the first 30 to 50 years (40).

In terms of evidence of the effect of the vaccine on a global scale in different countries, we can cite, for example, the United States after the implementation of the single dose vaccine in 1995, where cases and rates of varicella decreased in all age groups in surveillance zones with moderate vaccination coverage (41). In Canada, a 70\% decrease in hospitalization rates was observed in all age groups with the greatest impact on the 1-4 year age group. In Taiwan, the introduction and widespread use of the varicella vaccine led to a $75-80 \%$ decrease in the incidence of varicella in children. They also report an increase in HZ but do not attribute it to vaccination because the increase had already been observed even before implementation. Therefore, continuous monitoring is necessary to understand the dynamics of $\mathrm{HZ}$ (42). In this sense, there are revisions on a global scale where herd immunity and the absence of a definitive and consistent association between vaccination and the increase in the incidence of $\mathrm{HZ}$ (43) have been observed. European countries such as Germany, Italy and Spain with a simple dose scheme, for example, also report evidence of the impact where they declare a decrease in the incidences of Varicella in general (44) (45) (46). In the case of African countries, there is little existing information, apart from not having the varicella vaccine in their vaccination programs.In other countries with similar national programs to that of Argentina, varicella cases in pediatric patients who require hospitalizations involve mainly children after 5 years of a single-dose vaccination (47). In 2013, the National Immunization Program of Brazil (NIP) incorporated a live, attenuated tetraviral combined vaccine that includes measles, mumps, rubella and varicella (MMRV) in all the Brazilian states. This policy drove a reduction of hospitalizations (48) (49). Brazil has a cost-effectiveness study of the universal vaccination program against varicella in childhood through a dynamic model depending on age and time to estimate varicella incidence during 30 years. According to the results, the program has a positive impact on morbidity, health resources usage, and disease-related deaths (50). The model proposed a program based on a single-dose vaccination scheme, as in Argentina.

We can conclude that, at the global level, there is enough evidence about the effectiveness of the vaccine when given in two doses (51) (52). Evidence also shows the absence of change in varicella 
burden towards older age groups (53). In Argentina , there is information about the impact of the disease burden in terms of associated costs, mainly of health system resources. However, these studies are based on theoretical models, unlike this study, which incorporates varicella cases informed to the monitoring system (54). It is expected that costs decrease as incidence rates and hospitalization decrease, as it occurs in other countries (55) (56) (57).

We would like to mention some limitations of the presented study. The data we use consists of administrative data and clinically confirmed cases based. There is no laboratory confirmation leading to a possible bias due to misclassification of cases. It is an observational ecological study, therefore we cannot causally attribute the reduction of incidence rates to the vaccine implementation. Also, our study ignores spatial variation and possible local determinants that may act on the incidence rates such as climate variation and different time for vaccine implementation among provinces. Finally, the information on weekly cases for different age groups was unavailable. It would be interesting to explore the number of cases by age groups to see the impact of the vaccine on the target age group and also children not-vaccinated but protected due to a possible herd immunity effect. We consider explore data by province and different age groups in future work.

The present study is thus the first concrete evidence of the decrease in varicella incidence with a single-dose application program.

\section{Recommendations}

Epidemiological monitoring is a first step towards the evaluation of the single-dose program effectiveness, and the potential need of a second vaccine dose. Further studies are required to evaluate the duration and intensity of the vaccine implementation effect, as well as the indirect effect on non-vaccinated age groups. It is also convenient to perform a new cost study, incorporating the information derived from this research, and to study the impact in all the Argentine provinces. These results could derive in important implications for the current vaccination policies.

Prevention, through the implementation of programs based on laws is the action of higher impact on public health (58). An example of this is the vaccine implementation and the tasks carried out by the National Program of Control of Immunizable Diseases (NPCID). The objective of such program is to ensure coverage levels, especially under complex situations that countries might face, where vaccination coverages might become reduces due to discontinuations of this type of policies. For that reason, it is important that these public policies are reinforced and continue all political, social or economic contexts (59). On the other hand, and in agreement with the aforementioned facts, it is 
key to continue supporting strategies that derive in quality records both of health events and of coverage date, since they constitute the basis for generating of public policy impact.

\section{Funding}

The present scientific research was carried out with the support of the SALUD INVESTIGA "Dr. Abraam Sonis” grants, individual category, awarded by the National Health Ministry, through the Health Research Direction, Argentina.

\section{Conflicts of interest}

The authors declare no conflicts of interest.

\section{Acknowledgements}

- $\quad$ To the National Health Ministry, for the funding through the Salud Investiga grants, which allowed carrying out this study.

- To the National Epidemiological Monitoring System, who provided their valuable information.

\section{Highlights}

$>$ Evidencing the impact of the vaccine implementation in Argentina.

$>$ Describing the disease in the pre-vaccination era.

$>$ First monitoring of the post-vaccination era at the national scale.

$>$ Showing the performance of the vaccination program.

\section{References}

1. Seward JF, Zhang JX, Maupin TJ, Mascola L, Jumaan AO. Contagiousness of varicella in vaccinated cases: A household contact study. J Am Med Assoc. 2004;292(6):704-8.

2. Arvin AM. Varicella-zoster virus. Clin Microbiol Rev [Internet]. 1996;9(3):361-81. http://cmr.asm.org/content/9/3/361.abstract

3. Gould D. Varicella zoster virus: chickenpox and shingles. Nurs Stand [Internet]. 2014;28(33):52-8. http://rcnpublishing.com/doi/abs/10.7748/ns2014.04.28.33.52.e8249

4. Depledge DP, Sadaoka T, Ouwendijk WJD. Molecular aspects of varicella-zoster virus latency. Viruses. 2018;10(7):1-21.

5. Banz K, Wagenpfeil S, Neiss A, Hammerschmidt T, Wutzler P. The burden of varicella in Germany: Potential risks and economic impact. Eur J Heal Econ. 2004;5(1):46-53.

6. Gater A, Uhart M, McCool R, Préaud E. The humanistic, economic and societal burden of Herpes Zoster in Europe: A critical review. BMC Public Health. 2015;15(1):1-15.

7. Ávila-Agüero ML, Beltrán S, Castillo JB del, Castillo Díaz ME, Chaparro LE, Deseda C, et al. Varicella epidemiology in Latin America and the Caribbean. Expert Rev Vaccines [Internet]. 2018;17(2):175-83. http://dx.doi.org/10.1080/14760584.2018.1418327 
8. Bardach A, Cafferata ML, Klein K, Cormick G, Gibbons L, Ruvinsky S. Incidence and use of resources for chickenpox and herpes zoster in Latin America and the Caribbean--a systematic review and meta-analysis. Pediatr Infect Dis J [Internet]. 2012;31(12):1263-8. http://www.ncbi.nlm.nih.gov/pubmed/23188098

9. Ministerio de Salud Presidencia de la Nación. Fundamentos de la introucción de la vacuna contra rotavirus al calendario de inmunizaciones 2015. 2015;1-66.

http://www.msal.gob.ar/images/stories/bes/graficos/0000000586cnt-2014-12_lineamientosrotavirus.pdf

10. Barrenechea G.G; Vela R. P-SM. Relationship between climatic factors and cases of Varicella in Tucumán, Argentina. Investigación en Salud [Internet]. 2017;1(2):32. http://msptucuman.gov.ar/wordpress/wp-content/uploads/2018/07/Revista-2da-EdciónVersion-Web.pdf

11. Cenoz MG, Castilla J, Montes Y, Morán J, Salaberri A, Elía F, et al. Incidencia de la varicela y el herpes zóster antes de la introducción de la vacunación sistemática infantil en Navarra , 2005-2006 Varicella and herpes zoster incidence prior to the introduction of systematic child vaccination in Navarre , 2005-2006. 2008;30:2005-6.

12. Takahashi M. Vaccine Development. Infect Dis Clin North Am. 1996;10(3):469-88.

13. Salleras L, Salleras M, Soldevila N, Prat A, Garrido P, Domínguez Á. Vacunas frente al virus de la varicela zóster. Enferm Infecc Microbiol Clin [Internet]. 2015;33(6):411-23. http://dx.doi.org/10.1016/j.eimc.2015.05.005

14. Dennehy PH, Dennehy PH, Doctor D, Protocol J, Queries R, Network Z. Active Immunization in the United States: Developments over the past decade. 2007;14(4):872-908.

15. Organization WH. Varicella and herpes zoster vaccines: WHO position paper, June 2014. Wkly Epidemiol Rec. 2014;25(89):265-88.

16. Ministerio de Salud. Resolución 1029/2014. Programa Nacional de Control de Enfermedades Inmunoprevenibles. Incorporación. 2014.

17. World Health Organization. WHO vaccine-preventable diseases: monitoring system. 2018 global summary. World Health Organization. 2018.

18. Dirección de Control de Enfermedades Inmunoprevenibles. Coberturas de Vacunación por Jurisdicción Calendario Nacional de Vacunación 2009-2017 [Internet]. 2017. http://www.msal.gob.ar/images/stories/bes/graficos/0000001120cnt-2018_coberturasvacunacion-por-jurisdiccion-2009-2017.pdf

19. Sciences RB, Sato RC. Disease management with ARIMA model in time series Gerenciamento de doenças utilizando séries temporais com o modelo ARIMA. 2013;11(12):128-31.

20. Ministerio de Defensa. Instituto Geográfico Nacional [Internet]. Available from: http://www.ign.gob.ar/

21. Ministerio de Hacienda de la Nación Argentina. Instituto Nacional de Estadísticas y Censos [Internet]. https://www.indec.gob.ar/

22. R Core Team. R: A Language and Environment for Statistical Computing. Vienna, Austria: R Foundation for Statistical Computing; 2017.

23. Håvard R, Martino S, Chopin N. Approximate Bayesian Inference for Latent Gaussian Models Using Approximate Bayesian Inference for Latent Gaussian Models Using Integrated Nested Laplace Approximations. J R Stat Soc [Internet]. 2007; Series B(2001):1-28.

24. Rue H, Riebler A, Sørbye SH, Illian JB, Simpson DP, Lindgren FK. Bayesian Computing with INLA: A Review. 2016;(December):1-27.

25. Argentina C de la N. Proteccion De Los Datos Personales [Internet]. 2000. p. 1-15. http://servicios.infoleg.gob.ar/infolegInternet/anexos/60000-64999/64790/norma.htm

26. Yoshikawa T, Kawamura Y, Ohashi M. Universal varicella vaccine immunization in Japan. Vaccine [Internet]. 2016;34(16):1965-70. http://dx.doi.org/10.1016/j.vaccine.2016.02.058

27. Hattori F, Miura H, Sugata K, Yoshikawa A, Ihira M, Yahata Y, et al. Evaluating the effectiveness of the universal immunization program against varicella in Japanese children. 
Vaccine [Internet]. 2017;35(37):4936-41. http://dx.doi.org/10.1016/j.vaccine.2017.07.090

28. García Comas L, Latasa Zamalloa P, Alemán Vega G, Ordobás Gavín M, Arce Arnáez A, Rodero Garduño I, et al. Descenso de la incidencia de la varicela en la Comunidad de Madrid tras la vacunación infantil universal. Años 2001-2015. Aten Primaria. 2018;50(1):23-34.

29. Quian J, Rüttimann R, Romero C, Dall’Orso P, Cerisola A, Breuer T, et al. Impact of universal varicella vaccination on 1-year-olds in Uruguay: 1997-2005. Arch Dis Child. 2008;93(10):845-50.

30. Avila-Aguero ML, Ulloa-Gutierrez R, Camacho-Badilla K, Soriano-Fallas A, ArrobaTijerino R, Morice-Trejos A. Varicella prevention in Costa Rica: impact of a one-dose schedule universal vaccination. Expert Rev Vaccines [Internet]. 2017;16(3):229-34. Available from: http://dx.doi.org/10.1080/14760584.2017.1247700

31. Tafuri S, Fortunato F, Cappelli MG, Cozza V, Bechini A, Bonanni P, et al. Effectiveness of vaccination against varicella in children under 5 years in puglia, italy 2006-2012. Hum Vaccines Immunother. 2015;11(1):214-9.

32. Tanuseputro P, Zagorski B, Chan KJ, Kwong JC. Population-based incidence of herpes zoster after introduction of a publicly funded varicella vaccination program. Vaccine [Internet]. 2011;29(47):8580-4. http://dx.doi.org/10.1016/j.vaccine.2011.09.024

33. Sheridan SL, Quinn HE, Hull BP, Ware RS, Grimwood K, Lambert SB. Impact and effectiveness of childhood varicella vaccine program in Queensland, Australia. Vaccine [Internet]. 2017;35(27):3490-7. http://dx.doi.org/10.1016/j.vaccine.2017.05.013

34. Fu J, Wang J, Jiang C, Shi R, Ma T. Outbreak of varicella in a highly vaccinated preschool population. Int J Infect Dis. 2015;37(March 2010):e14-8.

35. Wutzler P, Bonanni P, Burgess M, Gershon A, Sáfadi MA, Casabona G. Varicella vaccination - the global experience. Expert Rev Vaccines [Internet]. 2017;16(8):833-43. http://dx.doi.org/ 10.1080/14760584.2017.1343669

36. Zhu S, Zeng F, Xia L, He H, Zhang J. Incidence rate of breakthrough varicella observed in healthy children after 1 or 2 doses of varicella vaccine: Results from a meta-analysis. Am J Infect Control [Internet]. 2018;46(1):e1-7. Available from:

https://doi.org/10.1016/j.ajic.2017.07.029

37. Brisson M, Melkonyan G, Drolet M, De Serres G, Thibeault R, De Wals P. Modeling the impact of one- and two-dose varicella vaccination on the epidemiology of varicella and zoster. Vaccine [Internet]. 2010;28(19):3385-97. http://dx.doi.org/10.1016/j.vaccine.2010.02.079

38. Lian I Bin, Chien YZ, Hsu PS, Chao DY. The changing epidemiology of varicella incidence after implementation of the one-dose varicella vaccination policy. Vaccine [Internet]. 2011;29(7):1448-54. Available from: http://dx.doi.org/10.1016/j.vaccine.2010.12.032

39. Marinelli I, van Lier A, de Melker H, Pugliese A, van Boven M. Estimation of age-specific rates of reactivation and immune boosting of the varicella zoster virus. Epidemics [Internet]. 2017;19:1-12. http://dx.doi.org/10.1016/j.epidem.2016.11.001

40. Brisson M, Gay NJ, Edmunds WJ, Andrews NJ. Exposure to varicella boosts immunity to herpes-zoster : implications for mass vaccination against chickenpox. 2002;20:2500-7.

41. Seward JF, Watson BM, Peterson CL, Mascola L, Pelosi JW, Zhang JX, et al. Varicella disease after introduction of varicella vaccine in the United States, 1995-2000. J Am Med Assoc. 2002;287(5):606-11.

42. Chao DY, Chien YZ, Yeh YP, Hsu PS, Lian IB. The incidence of varicella and herpes zoster in Taiwan during a period of increasing varicella vaccine coverage, 2000-2008. Epidemiol Infect. 2012;140(6):1131-40.

43. Varela FH, Pinto LA, Scotta MC. Global impact of varicella vaccination programs [Internet]. Vol. 15, Human Vaccines and Immunotherapeutics. Taylor \& Francis; 2019. 645-657 p. Available from: https://doi.org/10.1080/21645515.2018.1546525

44. Rieck T, Feig M, an der Heiden M, Siedler A, Wichmann O. Assessing varicella vaccine effectiveness and its influencing factors using health insurance claims data, Germany, 2006 
to 2015. Eurosurveillance. 2017;22(17):1-10.

45. Bechini A, Boccalini S, Baldo V, Cocchio S, Castiglia P, Gallo T, et al. Impact of universal vaccination against varicella in Italy: Experiences from eight Italian Regions. Hum Vaccines Immunother. 2015;11(1):63-71

46. Latasa P, Gil de Miguel A, Barranco Ordoñez MD, Rodero Garduño I, Sanz Moreno JC, Ordobás Gavín M, et al. Effectiveness and impact of a single-dose vaccine against chickenpox in the community of Madrid between 2001 and 2015. Hum Vaccines Immunother. 2018;14(9):2274-80.

47. Dinleyici EC, Kurugol Z, Kara A, Tezer H, Tas MA, Guler E, et al. Children with breakthrough varicella infection requiring hospitalization in Turkey (VARICOMP Study 2008-2013). Vaccine. 2015;33(32):3983-7.

48. Andrade AL, da Silva Vieira MA, Minamisava R, Toscano CM, de Lima Souza MB, Fiaccadori F, et al. Single-dose varicella vaccine effectiveness in Brazil: A case-control study. Vaccine. 2017;36:479-83.

49. Scotta MC, Paternina-de la Ossa R, Lumertz MS, Jones MH, Mattiello R, Pinto LA. Early impact of universal varicella vaccination on childhood varicella and herpes zoster hospitalizations in Brazil. Vaccine [Internet]. 2018;36(2):280-4. https://doi.org/10.1016/j.vaccine.2017.11.057

50. Valentim J, Sartori AMC, de Soárez PC, Amaku M, Azevedo RS, Novaes HMD. Costeffectiveness analysis of universal childhood vaccination against varicella in Brazil. Vaccine. 2008;26(49):6281-91.

51. Yin M, Xu X, Liang Y, Ni J. Effectiveness, immunogenicity and safety of one vs. two-dose varicella vaccination: a meta-analysis. Expert Rev Vaccines [Internet]. 2018;17(4):351-62. https://doi.org/10.1080/14760584.2018.1433999

52. Perella D, Wang C, Civen R, Viner K, Kuguru K, Daskalaki I, et al. Varicella Vaccine Effectiveness in Preventing Community Transmission in the 2-Dose Era. Pediatrics [Internet]. 2016;137(4):e20152802-e20152802. Available from: http://pediatrics.aappublications.org/cgi/doi/10.1542/peds.2015-2802

53. Baxter R, Tran TN, Ray P, Lewis E, Fireman B, Black S, et al. Impact of vaccination on the epidemiology of varicella: 1995-2009. Pediatrics [Internet]. 2014;134:24-30. http://www.ncbi.nlm.nih.gov/pubmed/24913796

54. Giglio N, Monsanto H, Rampakakis E, Yang HK, Kuter BJ, Wolfson LJ. Economic burden of varicella in children 1-12 years of age in Argentina, 2009-2014. J Med Econ [Internet]. 2018;21(4):416-24. Available from: http://dx.doi.org/10.1080/13696998.2018.1431919

55. Gil-Prieto R, Garcia-Garcia L, San-Martin M, Gil-de-Miguel A. Varicella vaccination coverage inverse correlation with varicella hospitalizations in Spain. Vaccine [Internet]. 2014;32(52):7043-6. http://dx.doi.org/10.1016/j.vaccine.2014.10.076

56. Al-Tawfiq JA, Abukhamsin A, Memish ZA. Epidemiology and impact of varicella vaccination: A longitudinal study 1994-2011. Travel Med Infect Dis [Internet]. 2013;11(5):310-4. http://dx.doi.org/10.1016/j.tmaid.2013.06.002

57. Waye A, Jacobs P, Tan B. The impact of the universal infant varicella immunization strategy on Canadian varicella-related hospitalization rates. Vaccine [Internet]. 2013;31(42):4744-8. http://dx.doi.org/10.1016/j.vaccine.2013.08.022

58. Diputados C de. Ley de Vacunas 2018. 1983; https://www4.hcdn.gob.ar/dependencias/dcomisiones/periodo-136/136-810.pdf

59. $\quad$ Nación C de D de la. Nueva Ley de Vacunas. 2018;1-9. https://www4.hcdn.gob.ar/dependencias/dcomisiones/periodo-136/136-810.pdf 